\title{
Test conditions greatly influence permeation of water soluble molecules through the intestinal mucosa: need for standardisation
}

\author{
M Peeters, M Hiele, Y Ghoos, V Huysmans, K Geboes, G Vantrappen, P Rutgeerts
}

\begin{abstract}
Permeability tests are widely used to investigate the pathogenesis of various gastrointestinal diseases including coeliac disease, infectious diarrhoea, and inflammatory bowel disease. In Crohn's disease they are used as activity parameters by some investigators. Lack of standardisation, however, makes it very difficult to compare data reported in different studies. The aim of this study was to gather permeation data in well controlled test conditions to standardise the methods. Nine healthy volunteers each received five consecutive permeability tests by mouth using polyethylene glycol400 (PEG-400) and ${ }^{51} \mathrm{Cr}$-EDTA as probe molecules. The probes were dissolved in water, a glucose solution, a starch solution, a hyperosmolar lactulosemannitol solution, and a liquid meal. A significantly decreased permeation for both probes was found when given with the hyperosmolar solution. The ${ }^{51} \mathrm{Cr}$-EDTA permeation was also decreased with water. The permeability index, ${ }^{51} \mathrm{Cr}$-EDTA/PEG-400, corrected for influencing factors, confirmed that the lactulose-mannitol solution and plain water yield lower values of macromolecule permeation than starch, glucose or liquid meal. Hyperosmolarity was clearly accompanied by a decrease in permeability probably caused by reversed solvent drag. Interindividual variability of probe permeation and permeability index is very low with a standard liquid meal. It is proposed that for permeability studies a standard liquid meal is always used.
\end{abstract}

(Gut 1994; 35: 1404-1408)

Gut permeability tests investigate the unmediated diffusion of the intestinal epithelium by medium and large sized, inert, nonmetabolised, and non-toxic water soluble molecules. Different molecules, including lactulose, cellobiose, mannitol, rhamnose, ${ }^{51} \mathrm{Cr}$-EDTA, and polyethylene glycol-400 (PEG-400) have been used as permeability probes. Two probes, PEG-400 (M $\mathrm{M}_{\mathrm{r}} 242-594$ and molecular diameter $5 \cdot 3 \AA$ ) and ${ }^{51}$ chromium labelled EDTA $\left(M_{r} 340\right.$ and molecular diameter $10.5 \AA$ ) are proposed to approximate to the characteristics of an 'ideal probe', ${ }^{2}$ although the use of PEG-400 as permeability probe has been criticised. ${ }^{34}$ Measurement of sugar probes in urine was

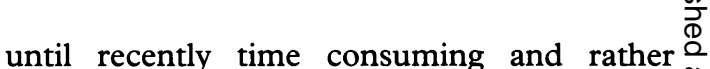
difficult. The high performance liquid \% chromatography technique rendered the oral $\overrightarrow{0}$ sugar test suitable for clinical use. ${ }^{5}$ An impor- $\vec{\overrightarrow{ }}$ tant advantage is that there is no radioactivity.

The oral permeability tests have been used

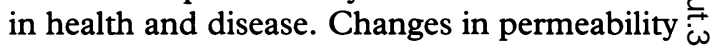
have been seen after intake of drugs, including non-steroidal anti-inflammatory drugs $\vec{O}$ (NSAIDs) $^{67}$ and methotrexate. ${ }^{8}$ Even $\vec{A}$ smoking $^{9}$ and alcohol intake ${ }^{10}$ induce changes in the permeation of macromolecules across 의 the gut wall. In gastrointestinal diseases - that $\overrightarrow{-}$ is, coeliac disease ${ }^{11} 12$ and Crohn's disease ${ }^{1314} O$ - permeability tests have been proposed for $\stackrel{\circ}{\circ}$ diagnosis and as activity parameters. They are $\underset{\mathbb{Q}}{ }$ easy to perform and can be used in children. In $\overrightarrow{0}$ Crohn's disease, it was suggested that the defect of the intestinal barrier function might be an aetiological factor in the pathogenesis of the disease. ${ }^{1516}$ The leaky gut would permit an increased penetration of antigens towards the immunological system of the bowel.

Lack of standardisation, however, is an important problem with permeability tests. It is difficult to compare results of permeability studies reported in published works because the methodology varies greatly. Although the main permeability pathway is paracellular, different probes show a variability in intestinal permeation. Also the ingested amount, the osmolarity of solutions, and the duration of $\frac{O}{3}$ urinary collection vary greatly in different studies.

The aim of this study was to investigate the $\frac{D}{0}$ influence of test conditions on the permeation of two water soluble molecules, ${ }^{51} \mathrm{Cr}$-EDTA $N$ and PEG-400, to standardise the method for $N$ the study of permeability.

\section{Methods}

SUBJECTS

Nine healthy volunteers (eight females and one $\frac{\vec{P}}{\mathbb{P}}$ male) with a mean age of 21 years (range $\stackrel{\odot}{\Phi}$

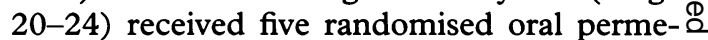
ability tests. None of them had any intestinal? complaints or had had previous bowel resec-8 tion. None of the subjects took NSAIDs or other drugs at the time of the test. Smoking

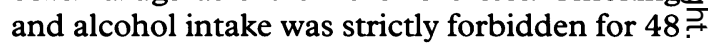
hours before the test.

\section{METHODS}

Five different test solutions containing the same amount of test probes were used in the 
consecutive tests: $250 \mathrm{ml}$ water, $50 \mathrm{~g}$ glucose $99 \%$ (Amylum, Aalst, Belgium) in $250 \mathrm{ml}$ water (1300 mmol/ $\mathrm{kg}), 250 \mathrm{ml}$ of Nutridrink, a polymeric solution containing $13 \%$ nonhydrolysed proteins (casein), 39\% fat and 48\% sugars with a total energy load of $635 \mathrm{~kJ} / 100$ $\mathrm{ml}$ and an osmolarity of $500 \mathrm{mmol} / \mathrm{kg}$ (Nutricia, Bornem, Belgium), $50 \mathrm{~g}$ starch (CPC, Vilvoorde, Belgium) in $250 \mathrm{ml}$ water, and a solution containing $1 \mathrm{~g}$ mannitol (Cerestar, Vilvoorde, Belgium) and $7 \mathrm{~g}$ lactulose $(10 \mathrm{ml}$ Bifiteral, Duphar-Weesp, The Netherlands) in $50 \mathrm{ml}$ water $(700 \mathrm{mmol} / \mathrm{kg})$. Each solution contained 10 g PEG-400 (UCB, Drogenbos, Belgium) and $50 \mu \mathrm{Ci}^{51} \mathrm{Cr}$-EDTA (Amersham International, Gent, Belgium) as permeability probes. The solutions were chosen as they are commonly used in permeability tests reported in published works. Glucose and starch were used to study the effect of these nutrient components on permeability.

Each solution was taken by the subjects after an overnight fast and normal food and fluid intake was permitted two hours after ingestion. Urine was collected during six hours. The excretion of the probes in the urine was measured and the intestinal permeation was expressed as a percentage of the ingested dose. A permeability index, ${ }^{51} \mathrm{Cr}-\mathrm{EDTA} / \mathrm{PEG}-400$, was calculated to correct for influencing factors. Minimal washout period between two tests was three days. Baseline excretion at the start of each test was calculated.

\section{ANALYSIS}

\section{PEG-400 analysis by gas chromatography}

The amount of PEG-400 in urine was measured by gas-liquid chromatography. Urine was collected in clean, dry plastic containers and stored at $0^{\circ} \mathrm{C}$. After measurement of the total volume, the urine was diluted to $1000 \mathrm{ml}$ and kept frozen at $-20^{\circ} \mathrm{C}$ until analysed. The analytical procedure was adapted from Jenkins ${ }^{4}$ and Chadwick. ${ }^{1} \mathrm{~A}$ $10 \mathrm{ml}$ volume of diluted urine and $2 \mathrm{ml}$ meso-erythritol solution (2 g/l, Cerestar, Vilvoorde, Belgium) was added to a Pyrex tube containing $8 \mathrm{~g}$ of $\mathrm{MB}-3$ resin (Merck, Darmstadt, Germany). The tube was vortexed for 20 seconds and allowed to stand an additional five minutes at room temperature. A 5 $\mathrm{ml}$ aliquot of the residual fluid was put into a Pyrex tube and was frozen in liquid nitrogen. The sides of the container were evenly coated by rotating. After freeze drying overnight, the sample was acetylated using $1 \mathrm{ml}$ of pyridine:acetic anhydride $(1: 2)$ and heated for two hours at $80^{\circ} \mathrm{C}$. The reaction was stopped by the addition of $1.25 \mathrm{ml}$ methanol. The sample was placed in a heating bath kept at $60^{\circ} \mathrm{C}$ and blown dry under a gentle stream of dry nitrogen. The sample was dissolved in 500 $\mu l$ ethylacetate:chloroform, volume $2: 1$ and was sonificated for 15 seconds.

The analysis was performed using a Chrompack CP9000 gas chromatograph (Middelburg, The Netherlands) equipped with the splitless injector and a flame ionisation detector. A $10 \mathrm{~m} 0.53 \mathrm{~mm}$ column was used with $2 \mu \mathrm{m}$ CP-Sil 5CB coating material (Chrompack, Middelburg, The Netherlands). A helium 5.5 (Air Products, Vilvoorde, Belgium) flow rate of $20 \mathrm{ml} / \mathrm{min}$ was used for the analysis. Injector and detector temperature was at $300^{\circ} \mathrm{C}$. The initial oven temperature was $150^{\circ} \mathrm{C}$ for three minutes. The oven temperature was then raised to $295^{\circ} \mathrm{C}$ and held at this temperature until the end. Peak areas were measured by PCI-software (Chrompack, Middelburg, The Netherlands) and calculated by means of an internal standard method. Nine peaks could be shown. The percentage composition of each molecular weight species was determined from the area under each peak and the total amount of PEG-400.

\section{Analysis of ${ }^{51} \mathrm{Cr}-\mathrm{EDTA}$}

Aliquots $(1 \mathrm{ml})$ of urine were counted for radioactivity by $\beta$ liquid scintillation counting (Compton electrons). The counter was a Packard, model 4430 (Downers Grove, Illinois, USA). Degree of quenching was measured by calibration curve and automatic correction for counting efficiency was done by computer.

\section{Statistics}

Data are given as mean (SD). Normality of data was verified by means of the ShapiroWilks test (SAS, Proc Univariate). A repeated measures analysis of variance (SAS, Proc ANOVA) was used to evaluate the effect of different test conditions in normal volunteers. If the multivariate test statistic (Wilks' $\lambda$ ) for a within subject effect of test conditions was significant at the $\mathrm{p}=0.05$ value, differences between the five conditions were evaluated by means of a contrast transformation.

\section{Results}

The Table summarises the effect of substrate on intestinal permeation (mean (SD)). Figure 1 shows the six hour fractional excretion of ${ }^{51} \mathrm{Cr}$-EDTA. There was a significant decrease in ${ }^{51} \mathrm{Cr}$-EDTA excretion after intake with the lactulose-mannitol solution $(0.17(0.07) \%)$ in comparison with a glucose solution $(0.65$ $(0.29) \%, p=0.0021)$, starch solution $(0.54$

\begin{tabular}{|c|c|c|c|c|c|}
\hline & Glucose & Nutridrink & Water & $\begin{array}{l}\text { Lactulose- } \\
\text { mannitol }\end{array}$ & Starch \\
\hline $\begin{array}{l}{ }^{51} \text { Cr-EDTA (\%) } \\
\text { PEG-400 (\%) } \\
\text { Cr-EDTA/PEG }\end{array}$ & $\begin{array}{c}0.65(0.29) \\
26.54(5.94) \\
0.024(0.008)\end{array}$ & $\begin{array}{c}0.50(0.06) \\
25.14(3.40) \\
0.020(0.003)\end{array}$ & $\begin{array}{c}0.31(0.13) \\
25.36(6.19) \\
0.012(0.005)\end{array}$ & $\begin{array}{c}0.17(0.07) \\
17.79(2 \cdot 41) \\
0.010(0.004)\end{array}$ & $\begin{array}{c}0.54(0.19) \\
25 \cdot 12(1.18) \\
0.220(0.008)\end{array}$ \\
\hline
\end{tabular}




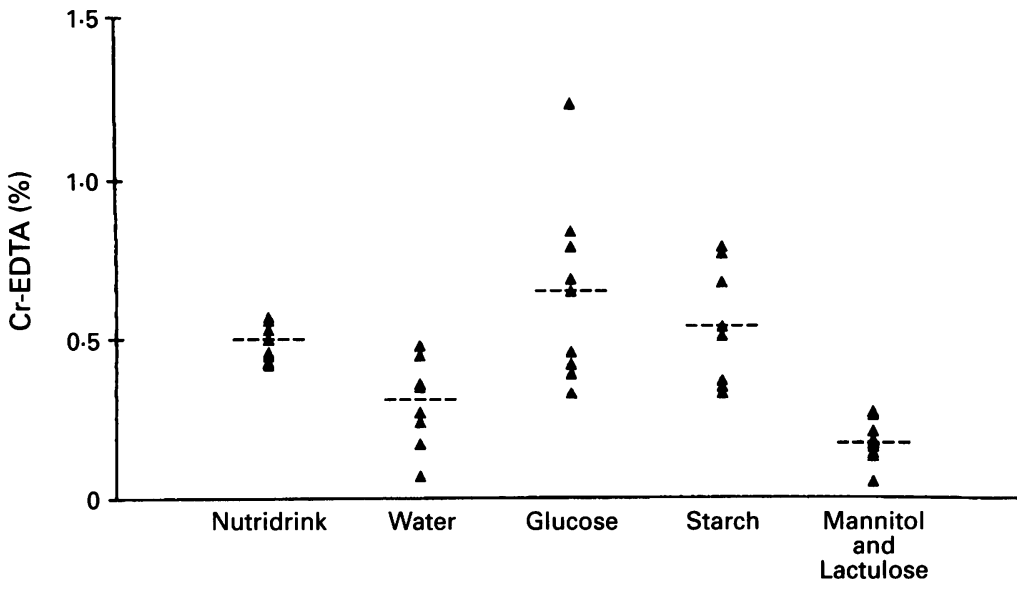

Figure 1: Effect of test solution on ${ }^{51} \mathrm{Cr}$-EDTA permeation.

$(0.19) \%, p=0.0002)$, the liquid meal $(0.50$ $(0.06) \%, p=0.0001)$ or water $(0.31(0.13) \%$, $\mathrm{p}=0.0022)$. A lower permeation was also found with water in comparison with a glucose solution $(p=0.0100)$, starch solution $(p=0.0023)$ or the liquid meal $(p=0.0060)$.

The total PEG-400 excretion was significantly lower after intake with the lactulosemannitol solution $(17.79 \quad(2.41) \%)$ in comparison with a glucose solution $(26.54$ $(5.94) \%, p=0.0020)$, a starch solution $(25 \cdot 12$ $(1 \cdot 18) \%, \mathrm{p}=0.0001)$, water $(25.36(6 \cdot 19) \%$, $\mathrm{p}=0.0088)$, and liquid meal $(25 \cdot 14(3.40) \%$, $\mathrm{p}=0.0001$ ) (Fig 2).

Figure 3 shows a typical chromatogram of the oligomers in PEG-400. Although total PEG-400 permeation was significantly decreased when given with a hyperosmolar solution, there was only a minor effect of test conditions on PEG oligomers excretion (Fig 4). A significant increase in permeation of the largest oligomers $\left(P_{6}, P_{7}, P_{8}\right)$ was found with starch.

The permeability index (Fig 5) showed a significantly decreased overall permeability for lactulose-mannitol solution $(0.010 \quad(0.004))$ compared with glucose $(0.024 \quad(0.008)$, $\mathrm{p}=0.0042)$, starch $(0.22(0.008), \mathrm{p}=0.0002)$, and liquid meal $(0.020(0.003), \mathrm{p}=0.0005)$. The index was also significantly decreased with water $(0.012(0.005))$. Interindividual variation of probe permeation and permeability index was lowest after liquid meal ingestion.

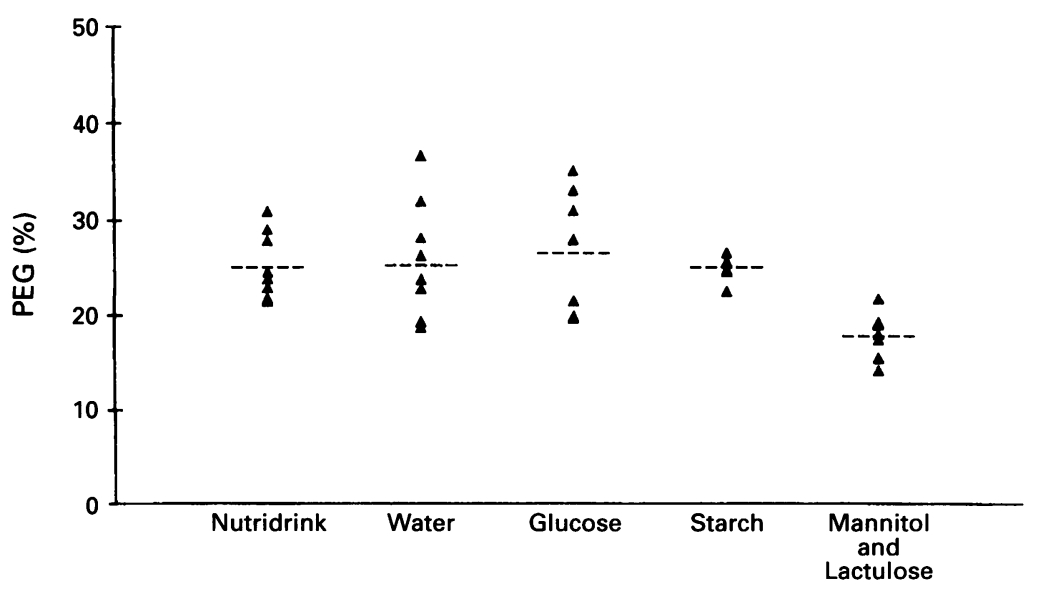

Figure 2: Effect of test solution on PEG-400 permeation.

\section{Discussion}

Many studies have reported on permeability of water soluble molecules across the intestinal wall in health and disease. Changes in permeability in normal volunteers resulting from the intake of drugs, ${ }^{68}$ alcohol, ${ }^{10}$ and smoking ${ }^{9}$ have been described. Permeability tests have been advocated as screening and diagnostic tests in coeliac disease ${ }^{1112}$ and changes in permeation were suspected to be of pathogenetic importance in Crohn's disease. ${ }^{15} 16$ Published reports on intestinal permeation of water soluble molecules are far from uniform in methodology. Cross study comparisons become very difficult. Many probes: mono and disaccharides, ${ }^{14}$ polyethylene glycols, ${ }^{4}$ and ${ }^{51} \mathrm{Cr}$-EDTA ${ }^{10}$ were used. None of these probes has been considered to approximate to the characteristics of an 'ideal' probe. The closest candidate is ${ }^{51} \mathrm{Cr}$-EDTA. ${ }^{2}$ An important disadvantage of this probe is its radioactivity. Sugar tests will probably become more attractive with newer and faster analysis techniques. These tests can be used in children and consecutive tests can be done in the same subject.

The permeability probes use different pathways to pass the intestinal barrier. Until recently the hypothesis explaining differences in the permeation of probes was based on 'the pore theory'. ${ }^{17}$ The smaller probes preferentially use the numerous smaller aqueous pores related to the tight junctions (paracellular) and to the aqueous channels in the enterocyte membrane (transcellular). The larger molecules use only the large pores, which are less numerous and related to the tight junctions ${ }^{18}$ (paracellular). Although it has been suggested that there exists a trans and paracellular pathway for these molecules, there was no experimental evidence for this theory until now. New knowledge about the intestinal epithelium resulted in the alternative 'paracellular theory'. 19 The predominant pathway for water soluble probe permeation is paracellular. This route is regulated by the tight junctions situated just below the brush border. The tight junctions are dynamic structures because of the linkage with the cytoskeleton and permit the passage of macromolecules to some extent. There is a morphological difference between the tight junctions of the villus cells and those of the crypt cells. The strand density - that is, resistance - of the tight junctions of the villus cells is higher than that of the crypt cells. The first are tighter and more selective. On the other hand, they are more accessible to luminal compounds. Therefore, smaller probes like PEG-400 can approach and penetrate more easily the villus tip in comparison with the larger probes, like ${ }^{51} \mathrm{Cr}-\mathrm{EDTA}$, which must reach the less selective crypt epithelium. This explains why PEG-400 penetrates at a much higher rate than ${ }^{51} \mathrm{Cr}$-EDTA in test situations.

Study results may be affected by individual variation in gastric emptying, intestinal transit time and surface area, mucosal blood flow, and renal clearance. The last two factors can be compensated for by using two different probes. A calculated ratio is a more reliable index of mucosal permeability. Not only the probes 


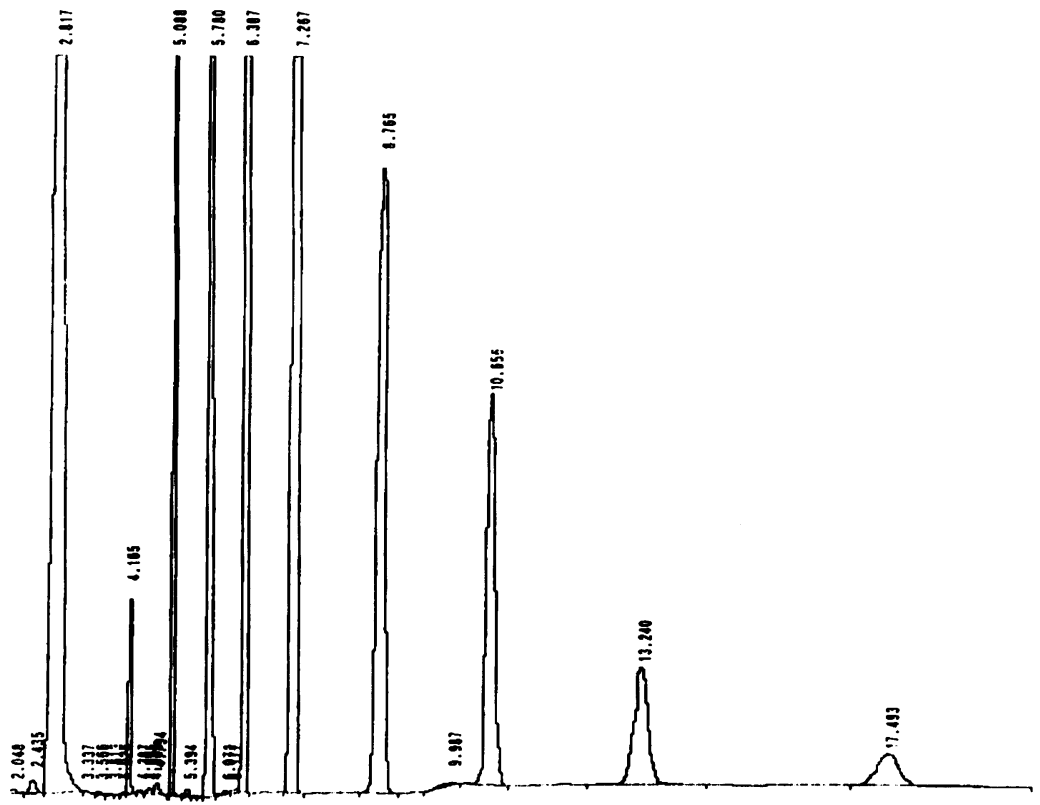

Figure 3: Standard chromatogram of the oligomers of PEG-400.

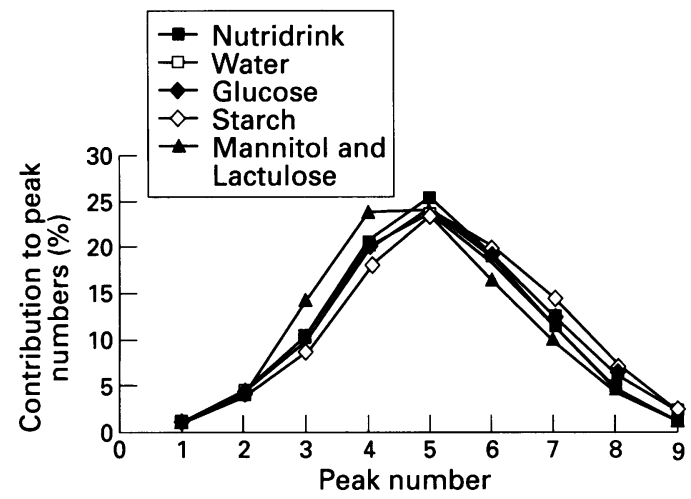

Figure 4: Effect of test solution on the different PEG-400 oligomers.

differ but also the osmolarity of the ingested solutions, the osmotic filler used, the ingested amount, the duration of urine collection, feeding status, and the use of agents known to influence permeability.

In this study, we tried to standardise for test conditions and examined the effect of some test substances on permeation of molecules in healthy volunteers. We used the conditions previously used for permeability studies - that is, hyperosmolar substrate ${ }^{20}$ (lactulose-mannitol),

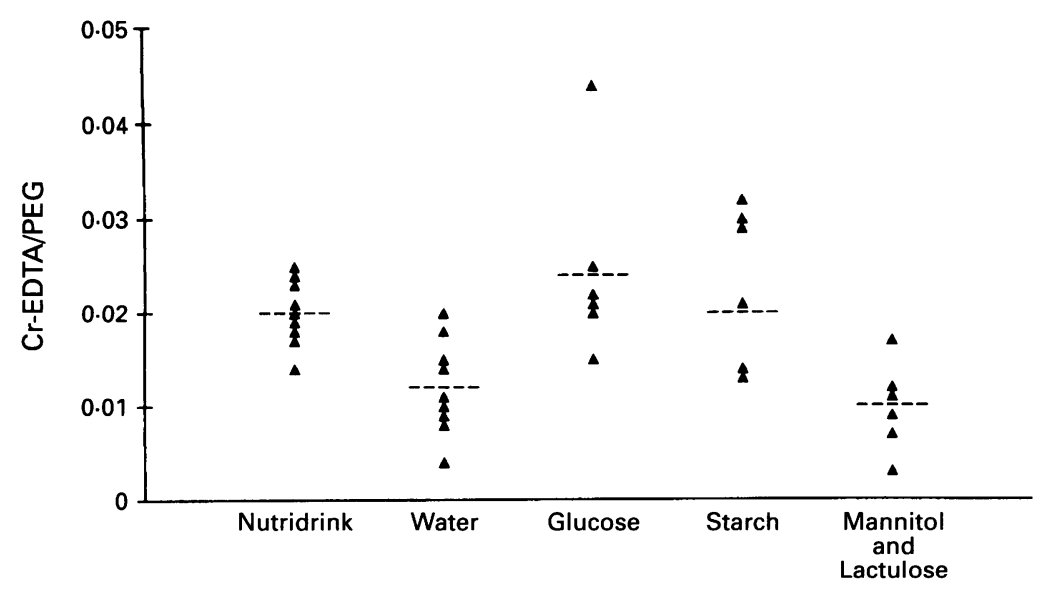

Figure 5: Effect of test solution on ${ }^{51} \mathrm{Cr}-E D T A / P E G-400$. plain water, ${ }^{1521}$ and a meal carrier. ${ }^{122}$ The other two substrates, glucose and starch, both important constituents of foods, were chosen to investigate the effect of their presence on intestinal permeability. The subjects had five consecutive tests. A significant decrease in PEG-400 and ${ }^{51}$ Cr-EDTA permeation and permeability index was found after intake with the hyperosmolar lactulose-mannitol solution. Studies in rats with lactulose as osmotic filler showed a decrease in ${ }^{51} \mathrm{Cr}$-EDTA permeability ${ }^{23}$ and Krugliak et al found a decreased PEG-400 absorption by increasing intraluminal osmolarity in rats. ${ }^{24}$ The driving force of permeation for both probes is probably the solvent drag. The addition of poorly absorbed osmotic fillers, lactulose and mannitol, increases the osmotic load in the lumen and reduces water absorption. Consequently the probe permeation is reduced. We think a hyperosmolar solution is less suitable for permeability studies, unless there is standardisation of the type of osmotic filler and a clear definition of the osmolarity used.

Although, the osmolarity is even higher for the glucose solution and almost the same for the liquid meal, the probes permeation is significantly higher than with the lactulosemannitol solution. A significant difference was not found for PEG-400 or for ${ }^{51} \mathrm{Cr}$-EDTA permeation between a glucose solution, a starch solution or a liquid meal. These solutions contain osmotic substances, which are absorbed very quickly and which induce solvent drag. It is hypothesised that in these three test conditions glucose governs the rate of permeation. The work of Pappenheimer et al 2526 in animals is crucial to the understanding of the mechanism of probe absorption when these test solutions are used. Comparatively small intraluminal concentrations of glucose (10-20 $\mathrm{mM}$ ) already saturate the $\mathrm{Na}$-coupled active carrier transport. The primary function of this carrier is to transport glucose in the intercellular space to provide the osmotic force for fluid absorption. It also induces a condensation of the perijunctional ring, however, increasing the permeability of the occluding junctions and it induces a dilatation of the intercellular lateral spaces. This link between active transport and the cytoskeletal structures at the tight junctions is the reason why the greatest part of the absorption of hydrophobic nutrients takes place by solvent drag. In humans, however, a recent study by Fine et $a l^{27}$ did not confirm the hypothesis that most glucose transport is passive and that there is direct influence of active glucose transport on the sieving characteristics of the tight junctions. Although glucose transport might be different in humans and animals, solvent drag is prob-ably the mechanism by which the two probes permeate the intestinal barrier, PEG-400 at the villus tip and ${ }^{51} \mathrm{Cr}$-EDTA at the crypts. Permeability results obtained with a standard meal are comparable with those of basic food constituents, starch and glucose, but in healthy volunteers the interindividual variation in permeability of the two probes is lowest with the meal. 
Analysis of percentage excretion of each oligomer (nine peaks) showed only small differences between different test solutions. We found an overall decrease after the lactulose-mannitol solution without loss of selectivity. With a starch solution there was a slight but significant tendency towards an increased permeation of the high molecular weight PEGs $\left(\mathrm{P}_{6}-\mathrm{P}_{8}\right)$. In general, the total amount of PEG excretion gives enough information about permeation for use as permeability tests in the clinical situation.

The duration of urine collection especially affects ${ }^{51} \mathrm{Cr}$-EDTA permeability. ${ }^{28} \mathrm{We}$ used a six hour collection mainly for two reasons. Firstly, we know that ${ }^{51} \mathrm{Cr}$-EDTA is preferentially absorbed in the duodenum and that after six hours the absorption is colonic. Our collection reflects small bowel permeability of ${ }^{51} \mathrm{Cr}$-EDTA. This is the reason why our results are lower than studies with a 24 hour collection. ${ }^{29}$ Secondly, it is generally accepted that in six hours most of the PEG-400 absorption is completed. ${ }^{3}$

We conclude that different factors influence the result of intestinal permeability tests. For interpretation and understanding of intestinal permeability, standardisation of the tests is needed. We propose to use a standard liquid meal for all permeability studies because it best mimics the physiological condition of daily food intake and the interindividual variation of permeation of the probes in healthy volunteers is limited. Glucose and starch, both important constituents of food do not change permeation to a great extent. ${ }^{51} \mathrm{Cr}$-EDTA is easy to use and the results are easier to interpret than with PEG-400. This probe is particularly suitable to investigate small bowel permeation.

1 Chadwick VS, Phillips SF, Hoffman AF. Measurements of intestinal permeability using low molecular weight polyethylene glycols (PEG 400). I. Chemical analysis and biological properties of PEG 400. Gastroenterology 1977; 73: 241-6.

2 Cooper BT, Small intestinal permeability in clinical practice. $\mathcal{F}$ Clin Gastroenterol 1984; 6: 499-501.

3 Teahon K, Smethurst P, Levi AJ, Menzies IS, Bjarnason I. Intestinal permeability in patients with Crohn's disease and their first degree relatives. Gut 1992; 33: 320-3.

4 Jenkins RT, Goodacre RL, Rooney PJ, Bienenstock J, Sivakumaran T, Walker WHC. Studies of intestinal permeability in inflammatory diseases using polyethylene glycol 400. Clin Biochem 1986; 19: 298-302.

5 Fleming SC, Kynaston JA, Laker MF, Pearson AD Kapembwa MS, Griffin GE. Analysis of multiple sugar probes in urine and plasma by high-performance anionexchange chromatography with pulsed electrochemical detection. Application in the assessment of intestinal permeability in human immunodeficiency virus infection. f Chromatogr 1993; 640: 293-7.

6 Krugliak P, Hollander D, Le K, Ma T, Dadfalza VD, Katz $\mathrm{KD}$. Regulation of polyethylene glycol 400 intestinal permeability by endogenous and exogenous prostanoids. permeability by endogenous and exogenous prostanoids. 1990; 31: 417-21.
7 Jenkins AP, Trew DR, Crump BJ, Nukajam WS, Foley JA, Menzies IS, et al. Do non-steroidal anti-inflammatory

8 Lifschitz CH, Mahoney DH. Low-dose methotrexate induced changes in intestinal permeability determined by polyethylene glycol polymers. F Pediatr Gastroenterol Nutr 1989; 9: 301-6.

9 Söderholm J, Olaison G, Sjödahl R, Tagesson C. Smoking and intestinal absorption of oral polyethylene glycols in Crohn's disease. Scand f Gastroenterol 1993; 28: 163-7.

10 Aabakken L. ${ }^{51} \mathrm{Cr}$-Ethylenediaminetetraacetic acid absorption test methodol

11 Martines D, Morris AI, Gilmore IT, Williams A, Stockdale $\mathrm{H}$, Critchley $\mathrm{M}$, et al. Comparison between the $\mathrm{H}$, Critchley $\mathrm{M}$, et al. Comparison between the detection of coeliac disease. Clin Science 1988; 75: 375-8.

12 Juby LD, Rothwell J, Axon ATR. Lactulose/mannitol: an ideal screen for celiac disease. Gastroenterology 1989; 96: 79-85.

13 Pironi L, Miglioli M, Ruggeri E, Levorato M, Dallasta MA, Corbelli C, et al. Relationship between intestinal permeability to ${ }^{51} \mathrm{Cr}$-EDTA and inflammatory activity in asymptomatic patients with Crohn's disease. Dig Dis Sci 1990; 35: 582-8.

14 Andre C, Descos L, Minaire Y. Comparison between lactulose-mannitol test and ${ }^{51} \mathrm{Cr}$-labelled ethylene diaminetetraacetate test in inflammatory bowel diseases. Hepatogastroenterology 1990; 37: 113-7.

15 Hollander D, Vadheim CM, Brettholz E, Petersen GM, Delahunty T. Rotter JI. Increased intestinal permeability in patients with Crohn's disease and their relatives - a possible aetiological factor. Ann Intern Med 1986; 105: 883-5.

16 May GR, Sutherland LR, Meddings JB. Is small intestinal permeability really increased in relatives of patients with Crohn's disease? Gastroenterology 1993; 104: 1627-32.

17 Travis S, Menzies I. Intestinal permeability: functional assessment and significance (editorial review). Clin Sci 1992; 82: 471-88.

18 Maxton DG, Bjarnason I, Reynolds AP, Catt SD, Peters TJ, Menzies IS. Lactulose, ${ }^{51}$ Cr-EDTA, L-rhamnose and polyethyleneglycol 500 as probe markers for assessment in polyethyleneglycol 500 as probe markers for assessment in vivo of $71-80$.

19 Hollander D. The intestinal permeability barrier. A hypothesis as to its regulation and involvement in Crohn's disease (review). Scand $\mathcal{F}$ Gastroenterol 1992; 27: 721-6.

20 Howden GW, Robertson C, Duncan A, Movis AJ, Russell RI. Comparison of different measurements of intestinal permeability in inflammatory bowel. $\mathrm{Am} \mathcal{f}$ Gastroenterol 1991; 86: 1445-9.

21 Ainsworth M, Eriksen J, Rasmussen JW, Schaffalitzky de Muckadell OB. Intestinal permeability of ${ }^{51} \mathrm{Cr}$-EDTA in patients with Crohn's disease and their healthy relatives. Scand I Gastroenterol 1989; 24: 993-8.

22 Philipsen EK, Batsberg W, Christensen AB. Gastrointestinal permeability to polyethylene glycol: an Gastrointestinal permeability to polyethylene glycol: an
evaluation of urinary recovery of an oral load of polyethylevaluation of urinary recovery of an oral load of polyethyl-
ene glycol as a parameter of intestinal permeability in ene glycol as a parameter of intestinal
man. Eur 7 Clin Invest 1988; 18: 139-45.

23 Bjarnason I, Smethurst P, Levi AJ, Peters TJ. Intestinal permeability to ${ }^{51} \mathrm{Cr}$-EDTA in rats with experimentally induced enteropathy. Gut 1985; 26: 579-85.

24 Krugliak P, Hollander D, Ma TY, Tran D, Dadufalza VD, Katz KD, et al. Mechanisms of polyethylene glycol 400 permeability of perfused rat intestine. Gastroenterology 1989; 97: 11 164-70.

25 Madara JL, Pappenheimer JR. Structural basis for physiological regulation of paracellular pathways in intestinal logical regulation of paracellular pathways

26 Pappenheimer JR. Paracellular intestinal absorption of glucose, creatinine, and mannitol in normal animals: relation to body size. Am f Physiol 1990; 259: G290-9.

27 Fine KD, Santa Ana CA, Porter JL, Fordtran JS. Effect of D-glucose on intestinal permeability and its passive absorption in human small intestine in vivo. Gastroenterology 1993; 105: 1117-25.

28 Elia M, Behrens R, Northrop C, Wraight P, Neale G. Evaluation of mannitol, lactulose and ${ }^{51} \mathrm{Cr}$-labelled ethylenediaminetetra-acetate as markers of intestinal permeability in man. Clin Science 1987; 73: 197-204.

29 Jenkins RT, Jones DB, Goodacre RL, Collins SM, Coates G, Hunt RH, et al. Reversibility of increased intestinal permeability to ${ }^{51} \mathrm{Cr}$-EDTA in patients with gastrointestinal inflammatory diseases. Am $₹$ Gastroenterol 1987; 82: nal inflam $1159-64$. 